$$
\begin{aligned}
& \text { LAMOCEY } \\
& \text { GRAIT } \\
& \text { IN-OZ-CR } \\
& \begin{array}{c}
18=273 \\
180
\end{array}
\end{aligned}
$$

FINAL REPORT

\title{
DESIGN OF HIGH-REYNOLDS-NUMBER \\ FLAT-PLATE EXPERIMENTS IN THE NTF
}

NASA GRANT NCC1-89

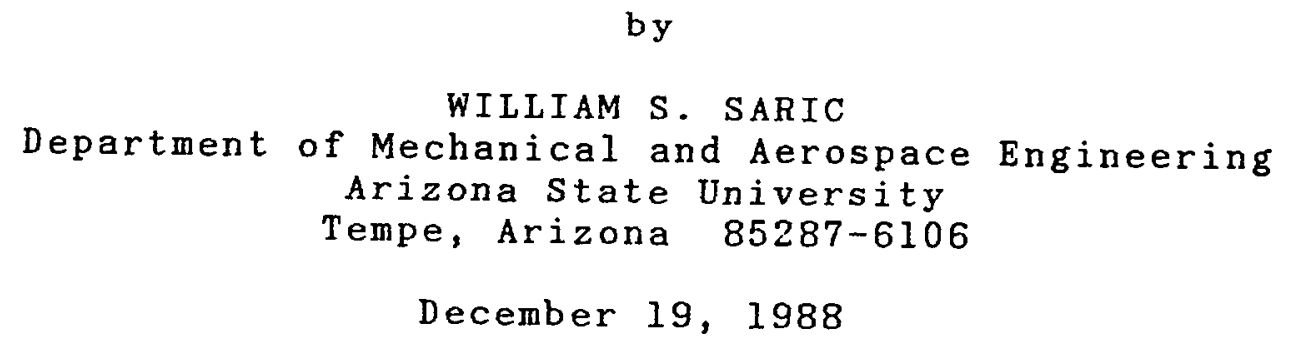




\section{Abstract}

The design of an experiment to measure skin friction and turbulent boundary-layer characteristics at Reynolds numbers exceeding $1 \times 10^{\circ}$ is described. The experiment will be conducted in a zero-pressure-gradient flow on a flat plate in the National Transonic Facility (NTF). The development of computational codes to analyze the aerodynamic loads and the blockage is documented. Novel instrumentation techniques and models, designed to operate in cryogenic environments, are presented. Special problems associated with aerodynamic loads, surface finish, and hot-wire anemometers are discussed. 
Final Report: Design of High-Reynolds

Number Flat-Plate Experiments in the NTF

\section{List of Symbols}

\section{Roman}

$C_{f}$ Local skin friction

$C_{F}$ Average skin friction

$C_{L}$ Lift coefficient at $M=0$

$C_{L}$ Lift coefficient at operating Mach number

$C_{p}$ Pressure coefficient

c Chord, $5.2 \mathrm{~m}$

$H$ Shape factor, $\delta * / \theta$

k Allowable roughness height

L Lift

M Mach number

m $\quad \sqrt{ } 1-M^{2}$

q Dynamic pressure

Re Reynolds number based on $x$

Re' Unit Reynolds number [ $\left.\mathrm{m}^{-1}\right]$

$S$ Area of plate, $12.5 \mathrm{~m}^{2}$

T Temperature

U Freestream velocity

v* Shear velocity, $\sqrt{t a n} / \mathrm{p}$

Greek

$\alpha$ Angle of attack (see Fig. 2)

$\Delta \quad$ Flap angle (see Fig. 2)

$\Delta C_{p}$ Pressure difference across plate

$\delta *$ Displacement thickness

$\theta$ Momentum thickness

$v \quad$ Kinematic viscosity

$\rho$ Density

$\tau_{n}$ Wall shear stress, $\mathrm{C}_{f} \rho \mathrm{U}^{2} / 2$

Subscripts

0 Conditions at $M=0$

1 Extreme test condition 
Final Report: Design of High-Reynolds

Number Flat-Plate Experiments in the NTF

Page 3

\section{Introduction}

Knowledge of the turbulent boundary-layer characteristics of high-speed flows is important for the design of any modern airtransport vehicle. The increase in size of these vehicles has pushed the aerodynamic design requirements to regions of higher chord Reynolds numbers, Re, that approach $1 \times 10^{\circ}$. For example, $\mathrm{Re}_{c}=60 \times 10^{6}$ on the 747 wings, $\mathrm{Re}_{c}=5 \times 10^{8}$ on the C5 fuselage, and $\mathrm{Re}_{\mathrm{c}}=1 \times 10^{9}$ on the $\mathrm{B}-1$ fuselage. Submarines routinely have Reynolds numbers that exceed $1 \times 10^{\circ}$. At the present $t$ ime, these Reynolds numbers can be a factor of 6-100 times greater than those obtainable by existing facilities.l Moreover, there is a dearth of fundamental data on skin friction and velocity profiles at these Reynolds numbers for even the case of a zero-pressuregradient, flat-plate flow.

Figure 1 shows the effect of Reynolds number on flat-plate skin friction in the high-Reynolds-number range. For convenience, only those data of winter et al.2 are included. other data at lower Reynolds numbers are 25-40 years old. The empirical curves ${ }^{3-6}$ show divergence when extended to the Reynolds number range of interest but not surprisingly since they were based on lower Reynolds number data (see White for additional empirical models). This situation indicates further complications when estimates are made for the case of roughness or non-zero pressure gradient.

With the anticipated operational use of the National Transonic Facility (NTF), we have the capability to do research and development in high-Reynolds-number flows. of particular interest are data essential for evaluating turbulence theories and estimating high-Reynolds-number drag. Besides basic skinfriction data, many other unknowns exist. For example, the nature of large-scale structures within the turbulent boundary layer at high Reynolds numbers is uncertain. Indeed, their very existence in the Reynolds-number range of $10^{\circ}$ can be questioned. Ultimately, the role of wall roughness, forward and backward facing steps, cavities, protuberances, and pressure gradients must be evaluated. Moreover, extensions to high Reynolds numbers of the basic results of turbulent-drag-reduction programs must be carried out.

The zero-pressure-gradient, flat-plate flow is the intrinsic part of these more complicated flows. Therefore, a careful flatplate experiment at high Reynolds numbers serves to establish a bench mark for future experimental work and theoretical modeling. This bench mark will extend the data base upon which future work will be done. The initial work will concentrate on basic skinfriction data with additional hot-wire measurements to explore the boundary-layer velocity profiles. 
Final Report: Design of High-Reynolds

Number Flat-Plate Experiments in the NTF

Page 4

\section{Test Conditions}

The general description and capabilities of the NTF are given by Fuller.8 Therefore, only a few basic features are presented here. The NTF is a cryogenic, continuous-flow, highpressure wind tunnel capable of operating at unit Reynolds numbers of up to $450 \times 10^{6} \mathrm{~m}^{-1}$. The test section is $2.5 \mathrm{~m}$ square and $7.6 \mathrm{~m}$ long with a slotted-wall configuration. Moreover, the initial configuration will have all of the slots closed. The test-section geometry can also be varied by slightly deflecting the upper and lower walls about a pivot point at the test-section entrance. This will be used to balance the displacementthickness effects on the upper and lower walls during the zeropressure-gradient tests.

The temperature range of the facility extends from $100^{\circ} \mathrm{K}$ to $340^{\circ} \mathrm{K}$. In a range of Mach numbers around 0.7 , chord Reynolds numbers can exceed $1.5 \times 10^{9}$ on a model $4 \mathrm{~m}$ long. The highReynolds-number, high-dynamic-pressure test conditions occur for the low-temperature range of the facility and present a special set of problems with regard to models and instrumentation. Therefore, the test design uses the following conditions as extreme goals.

\section{Extreme Test Conditions}

Maximum Mach number $M_{1}=0.7$

Maximum dynamic pressure: $q_{1}=2 \mathrm{~atm}=2 \times 10^{5} \mathrm{~Pa}\left(43001 \mathrm{~b} / \mathrm{ft}^{2}\right)$

Minimum temperature $=T_{1}=100^{\circ} \mathrm{K}\left(-270^{\circ} \mathrm{F}\right)$

Maximum unit Reynolds number: $\operatorname{Re}_{1}^{\prime}=450 \times 10^{6} / \mathrm{m}\left(137 \times 10^{6} / \mathrm{ft}\right)$

Maximum wetted length: $4.1 \mathrm{~m}$

Maximum Reynolds number: $1.85 \times 10^{\circ}$

The corners of the test matrix can be defined using Fuller. For non-cryogenic operation, say air at $250^{\circ} \mathrm{K}$, it is possible to achieve $R e=0.6 \times 10^{9}$ at $M=0.7$. For low-Mach-number operation, say $M=0.3$, one obtains $R e=0.7 \times 10^{9}$ at $T=100^{\circ} \mathrm{K}$. At $M=0.7$ and $T=100^{\circ} \mathrm{K}, R e=1.85 \times 10^{\circ}$ can be achieved without having locally supersonic flow. Thus one can see that measurements can be made independent of either Mach number or static temperature. Thus, the role of Mach number and static temperature (although not considered to be important) will be evaluated along with Reynolds-number effects.

It has been established 910 that it is feasible to conduct experiments of this kind in a cryogenic environment. Kilgore et al.' did low Mach-number experiments on laminar boundary layers where the temperature was varied while the Reynolds number was held constant and observed no important differences. Adcock and Johnsonil did computational simulations of turbulent boundary layers and showed that $C_{f}$ was within $\pm 0.5 \%$ when real-gas effects were included at cryogenic temperatures and pressures characteristic of NTF. Of course, one of the tenets of this 
Final Report: Design of High-Reynolds

Number Flat-Plate Experiments in the NTF

Page 5

program is to establish the validity of such computational models in these environments.

\section{Model}

The proposed experiment consists of a vertically-mounted flat plate that spans the tunnel as a splitter plate. In this configuration, the flat-plate flow is contaminated by turbulence and spanwise variations generated at the leading-edge/floor junction. The spreading angle is in the range of $11^{\circ}$ to $15^{\circ}$, therefore, one can obtain about $4.6 \mathrm{~m}$ of uncontaminated flow. The pressure recovery from the trailing-edge flap moves upstream and begins to affect the flow at $x=4.1 \mathrm{~m}$ for a $5.2 \mathrm{~m}$ plate. Therefore, we make the conservative estimate that the maximum useful chord will extend to $x=4.1 \mathrm{~m}$.

The flat plate is $50 \mathrm{~mm}$ (2") thick with an overall $5.2 \mathrm{~m}$ chord (including leading edge and flap) and $2.5 \mathrm{~m} s p a n$. It is made of an aluminum skin, aluminum honeycomb construction. All parts and fixtures of the entire test assembly are made of 6061T6 aluminum in order to avoid problems of differential thermal expansion. The skin thickness is $4.8 \mathrm{~mm}\left(3 / 16^{\prime \prime}\right)$ consistent with strength requirements. The honeycomb is perforated and is 41.3 $\mathrm{mm}\left(1-5 / 8^{\prime \prime}\right)$ deep with a $6.4 \mathrm{~mm}\left(1 / 4^{\prime \prime}\right)$ cell size. An epoxy certified to operate at $100^{\circ} \mathrm{K}$ is used. A number of special requirements have been developed to assure ourselves of achieving the test goals, and these are described in the subsequent sections.

\section{A. Surface Waviness}

Special care must be taken to control the surface waviness. The allowable amplitude $A$, of departures from flatness over a distance $D$, is given by $A / D<0.002$. This criterion restricts the error in the skin-friction measurement to less than $1 \%$ and follows from the work of Lin et al.1l Because of this restriction, a large autoclave $(3 \mathrm{~m} \times 6 \mathrm{~m})$ is used in the assembly of the model.

\section{B. Surface Roughness}

Because of the thin boundary layers, a very smooth and polished surface is required. A very conservative estimatelz of the maximum allowable roughness height, $k$, is given by

$$
k=\sqrt{50} / \mathrm{C}_{\mathrm{f}} / \mathrm{Re}^{\prime}
$$

where $C_{f}$ is the skin-friction coefficient and $R^{\prime}$ is the unit Reynolds number. Equation (l) is derived by assuming that a surface is hydraulically smooth if all of the protuberances are contained within the laminar sublayer. This is true for $v * k / v<5$ 
Final Report: Design of High-Reynolds

Number Flat-Plate Experiments in the NTF

Page 6

where $v *$ is the shear velocity $\sqrt{ } \tan _{n} / \rho$. For the extreme test conditions, $k=17$ microinches over the test portion of the plate. Therefore, the plate surface-roughness criterion is 14 microinch absolute and 12 microinch rms. Thus, careful hand polishing of the surface is required.

\section{Leading Edge and Trailing Edge}

The leading edge is a symmetric ellipse with a $12: 1$ ratio of major to minor axes. Its chord is $0.3 \mathrm{~m}$ and is made from a solid piece of aluminum. This configuration gives a good stagnation point and a tangent to the flat plate with only a small pressure gradient in the leading-edge region. It will be shaped on a numerically-controlled mill to hold the spanwise nonuniformities near the leading edge to the \pm 0.001 inch, after which it will be polished. A small strip on the leading edge will be left unpolished, and this should be sufficient to fix the transition location.

A trailing-edge flap is used to control the position of the attachment line on the leading edge by balancing the blockage between the two sides of the plate. The position of the flap is mechanically actuated to provide the desired flow conditions at different freestream velocities.

Figure 2 shows the basic plate/flap configuration inside the tunnel. The plate is off-center and over the third slot from the far wall. The plate is at a slight negative angle of attack because of displacement-thickness blockage. The flap is adjusted to minimize the overall circulation.

\section{Flow-Field Calculations}

A number of tasks are defined under flow-field calculations that must be carried out before model fabrication and testing begin. They are: (A) allowable pressure gradient for zeropressure-gradient flow, (B) wall interference and blockage, and (C) aerodynamic loads on the model.

The basic tools for the calculations are the panel-method code of Bristow and the turbulent boundary-layer code of Anderson and Lewis.14 These are used separately and in a combined version. 15

\section{A. Allowable Variation in $C_{p}$}

In order to establish a criterion for zero-pressure-gradient flow, we assume that a local pressure gradient must not change the local skin friction by $1 \%$ over the zero-pressure-gradient case. The momentum-integral equation ${ }^{12}$ is usually written in the following form 
Final Report: Design of High-Reynolds

Number Flat-Plate Experiments in the NTF

Page 7

$$
\tau_{\mathrm{w}} / \rho=(2 \theta+\delta *) \frac{\mathrm{dU}}{\mathrm{dx}}+\mathrm{U}^{2} \frac{\mathrm{d} \theta}{\mathrm{dx}}
$$

where $\tau_{*}$ is the wall shear stress, $U(x)$ is the freestream velocity, $\theta$ is the momentum thickness, and $\delta *$ is the displacement thickness. We need a relationship between the skin-friction coefficient and the gradient of the pressure coefficient so by using the definitions of $C_{f}, C_{p}$, and the shape factor $H$, the momentum-integral equation (2) can be rewritten as

$$
\mathrm{C}_{f}=-(2+\mathrm{H}) \theta \frac{\mathrm{dC}}{\mathrm{dx}}+3\left(1-\mathrm{C}_{\mathrm{p}}\right) \frac{\mathrm{d} \theta}{\mathrm{dx}}
$$

For a zero pressure gradient

$$
C_{f}^{0}=2 \frac{d \theta^{0}}{d x}
$$

where superscript "denotes the zero-pressure-gradient reference point. By introducing a pressure gradient $\mathrm{dC}_{p}^{\prime} / \mathrm{dx}$ into Equation (3), the other parameters change as $\mathrm{C}_{f}=\mathrm{C}_{\mathrm{f}}^{a}+\mathrm{C}_{f}^{1}, \theta=\theta^{0}+\theta^{\prime}$, $\mathrm{H}=\mathrm{H}^{0}+\mathrm{H}^{\prime}$. Then the change in skin friction for a given gradient in $C_{p}$ can be written as

$$
\frac{\Delta \mathrm{C}_{f}}{\mathrm{C}_{f}^{0}}=\left[-\left(2+\mathrm{H}^{n}\right) \frac{\mathrm{dC}_{\mathrm{n}}^{\prime}}{\mathrm{dx}}+\frac{1}{\theta^{0}} \frac{\mathrm{d} \theta^{0}}{\mathrm{dx}}\right] /\left(\frac{1}{\theta^{0}} \frac{\mathrm{d} \theta^{n}}{\mathrm{~d}}\right)
$$

where $\Delta C_{f}=C_{f}^{\prime}-C_{f}^{0}$. Equation (5) relates the change in skin friction as a function of the pressure gradient and the gradient of the perturbation of the momentum thickness.

It is necessary to develop means for evaluating $\mathrm{d} \theta / / \mathrm{d} x$. This is done using an approximation based on Buri's methodiz for boundary layers with pressure gradients (see pp. 678-679 of Schlichtingl2). It can be shown after considerable algebra that to within the order of $(0.01) \mathrm{Re}_{\mathrm{q}}^{-1 / 4}$ :

$$
\frac{\mathrm{d} \theta^{\prime}}{\mathrm{dx}}=\mathrm{A} \theta^{n} \frac{\mathrm{dC}^{\prime}}{\mathrm{dx}}
$$

Where $A$ is a positive constant* of order one. Then Equation (5) is rewritten as

$$
\frac{\Delta \mathrm{C}_{f}}{\mathrm{C}_{\mathrm{f}}^{0}}=-\left[\frac{2+\mathrm{H}^{\mathrm{n}}}{2}-\mathrm{A}\right] \frac{\mathrm{d} \mathrm{C}_{f}^{\prime}}{\mathrm{dx}} /\left(\overline{\theta^{\mathrm{n}}} \frac{\left.\mathrm{d} \frac{\theta^{0}}{\mathrm{~d} \mathrm{x}}\right)}{}\right.
$$

In terms of an allowable $\Delta \mathrm{C}_{f} / \mathrm{C}_{f}^{n}$, the allowable $\mathrm{dC}_{p}^{\prime} / \mathrm{dx}$ can be expressed as

$$
\left.\frac{\mathrm{dC}_{f}^{\prime}}{\mathrm{dx}}\right) \text { allowable }=-\frac{\mathrm{C}_{f}^{n}}{\theta^{n}} \frac{1}{2+\mathrm{H}^{n}-2 \mathrm{~A}}\left(\frac{\Delta \mathrm{C}_{f}}{\mathrm{C}_{f}^{0}}\right)
$$

*In terms of Buri's method, $A=2 n / 5$ where $n=3.94$ and is defined in Equation 22.15 of Schlichting.12 
Final Report: Design of High-Reynolds

Number Flat-Plate Experiments in the NTF

Page 8

The constant, A, can be determined using selected boundary-layer calculations using Ref. (14) with Buri's approximation. Thus Equation (7) (whose final form was suggested by Nagib ${ }^{16}$ ) can be used as an approximate tool for estimating the allowable pressure gradient for an allowable error in $C_{f}$. Moreover, Equation (7) defines a means for simplifying the number of turbulent boundary layer calculations by permitting a local evaluation with zero pressure gradient results. For the Reynolds number range of $10^{\circ}$, calculations show that

$$
\left.\frac{\mathrm{dC}_{f}^{\prime}}{\mathrm{dx}}\right) \text { allowable }=\left\langle-7\left(\frac{\mathrm{C}_{f}^{0}}{\theta^{0}}\right)\left(\frac{\Delta \mathrm{C}_{f}}{\mathrm{C}_{f}^{0}}\right)\right.
$$

For the conditions of the present experiment, given an allowable error in $\mathrm{C}_{\text {f }}$ of $\pm 1 \%$, a conservative allowable pressure gradient is $\mathrm{dC}_{\mathrm{p}}^{\prime} / \mathrm{dx}< \pm 2 \times 10^{-4} / \mathrm{cm}$ at $3 / 4$ chord.

\section{B. Wall Interference and Blockage}

A large number of turbulent boundary-layer calculations were made under different flow conditions within the test matrix. Based on the criterion given in Equation (8), it appears as though a plate orientation of approximately $-0.1^{\circ}$ angle of attack will account for displacement-thickness effects over the model. (See Figure 2 for plate orientation.) However, in order to establish this more accurately and to assure ourselves that wall liners and wall modifications are not required, the inviscid code $^{13}$ and the viscous code ${ }^{14}$ are combined into a single blockagecalculation code. ${ }^{15}$

The $C_{p}$ distribution of the tunnel (beginning in the settling chamber) and of the plate (for some initial orientation of Figure 2) are calculated first. These results are used to calculate the boundary layers on the sidewalls and on the plate. The shapes of the wall and of the plate are changed by adding the displacement thickness and the inviscid code is rerun. Only the blockage of the sidewalls is used since the positions of the floor and ceiling surfaces are adjusted independently for zero pressure gradient. This process is repeated until convergence. The angle of attack of the plate is varied in order to flatten the $C_{p}$ distribution to almost zero $\mathrm{dp} / \mathrm{dx}$, and the flap is adjusted to prevent separation on the test side of the leading edge. The inviscid calculations are done for $M=0$ and the $C_{p}$ distribution is scaled using the Prandtl-Glauret rule where

$$
C_{p}=C_{p \dot{u}}\left(1-M^{2}\right)^{-1 / 2}=C_{p \dot{v}} / m
$$

The boundary-layer code is run at $M=0.7$ considering this to be the most extreme condition. There are no locally supersonic regions in the flow at this Mach number.

Figure 3 is a plot of $-C_{p i} v s x / c$ on the test side of the plate for an angle of attack of $\alpha=-0.08$ and a flap angle of $\Delta=-$ 
Final Report: Design of High-Reynolds

Number Flat-Plate Experiments in the NTF

Page 9

1.0. Between $\mathrm{x} / \mathrm{c}=0.15(\mathrm{x}=.78)$ and $\mathrm{x} / \mathrm{c}=0.8(\mathrm{x}=4.1 \mathrm{~m}), \mathrm{dC}_{\mathrm{f}}^{\prime} / \mathrm{dx}<$ $1.0 \times 10^{-4} / \mathrm{cm}$ which meets the requirements given in the discussion after Equation (8). The following table gives the values of the pressure gradient at $M=0.7$ for different chord locations.

$\begin{array}{lc}\mathrm{x} / \mathrm{c} & \mathrm{dC}_{\mathrm{p}} / \mathrm{dx} \times 10^{4} \mathrm{~cm} \\ 0.117 & 3.71 \\ 0.161 & 1.13 \\ 0.214 & 0.71 \\ 0.390 & 0.13 \\ 0.507 & -0.001 \\ 0.683 & -0.04 \\ 0.742 & -0.36 \\ 0.800 & -1.06 \\ 0.860 & -5.00\end{array}$

The normalized numbers in the second column can be interpreted as $\mathrm{dC}_{\mathrm{p}}$ in \% per meter.

Thus it is shown that a zero-pressure-gradient flow can be established with a uniform angle of attack of the plate without resorting to sidewall modifications. This is known to be true for incompressible flows and is possible here provided the Mach number does not exceed 0.7 . These results will be confirmed by conducting a scale model test in the Diffuser Flow Apparatus ${ }^{17}$ at NASA Langley Research Center. The slightly negative $C_{p j}$ shown in Figure is accounted for in the boundary-layer measurements by determining the virtual leading edge.

\section{Aerodynamic Loads}

Figure 2 shows the model configuration as it is placed inside the tunnel. The conventions for the directions of lift, angle of attack, and flap are also shown. This is not a scale drawing. The average lift forces scale with the Prandtl-Glauret rule and are given by

$$
L=C_{L 0} q_{1} S\left(1-M_{1}^{2}\right)^{-1 / 2}
$$

where $C_{L_{0}}$ is the lift coefficient determined by integrating, along $\mathrm{x} / \mathrm{c}$, the difference of the pressure coefficient, $\Delta C_{p y}$, on each side of the plate.

Figure 4 gives $\Delta C_{p y}$ along the model for $\alpha=-0.08^{\circ}$ and $\Delta=-$ $1.0^{\circ}$. The angle of attack produces a zero dp/dx over the test side of the plate and a pressure drop along the back side of the plate. Under these conditions, $C_{L_{0}}=\# 0.030$ (the lift is positive and in the direction shown in Figure 2), and the total lift under extreme conditions is $1.1 \times 10^{5} \mathrm{~N}(25,0001 \mathrm{bs}$.$) which$ represents an average loading of $8.5 \mathrm{kPa}$ ( $1.2 \mathrm{psi}$ ). The loads in the leading edge and the flap are each $11,000 \mathrm{~N}(2500 \mathrm{lb}$. 
Final Report: Design of High-Reynolds

Number Flat-Plate Experiments in the NTF

Page 10

assuming an average $C_{L 0}$ of 0.05 . The presence of the tunnel walls essentially doubles the lift over the no-wall case (an external flow). For example, with zero flap deflection we find that $\mathrm{C}_{\mathrm{L}_{0}} \approx 4 \pi \alpha$.

The flap position can strongly effect the overall lift on the plate. For example, $\Delta=-1.5^{\circ}$ gives $C_{L_{0}}=+0.054$ while $\Delta=-0.5^{\circ}$ gives $C_{L_{0}}=-0.0072$. By setting the flap angle with slightly positive $C_{L 0}$, the position of the attachment line on the leading edge does not separate the flow on the test side and compensates for extra blockage on the non-test side of the model due to instrumentation. The flap position is adjustable during the test because there is no way to account for this blockage. All load calculations are done at $M=0.7$ although $C_{p o}$ and $C_{L 0}$ are used for reference.

A computer code is written to calculate the deflections of the model using plate theory under load conditions typical of Figure 4. It assumes that the web of the honeycomb offers no strength and that all of the load is taken in the skin. The plate loading of 1.2 psi is well within the strength characteristics of the model. What is necessary, however, is to restrict the plate deflections so as not to violate the surface waviness criterion of section III.A or the allowable pressure gradient criterion of Equation ( 8 ) in section IV.B. It is assumed the plate has six supporting struts on the non-test side located at $1 / 4,1 / 2,3 / 4$ chord and $1 / 3,2 / 3$ span. Small wideflanged beams extend along the chord at these span locations. Fixed-end supports at the floor and ceiling are also assumed. Maximum deflection occurs mid-span at $x / c=0.63$ where $\Delta C_{p i}=0.03$. For the model configuration of section III, the maximum deflection is found to be $0.3 \mathrm{~mm}\left(0.012^{\prime \prime}\right)$. This is well with the surface waviness criterion.

\section{Instrumentation}

The model is instrumented with static-pressure ports, shearstress gauges, thermocouples, strain gauges, and an accelerometer. Single location boundary-layer measurements are conducted with a total-pressure tube and a hot wire mounted on a variable jack set through the shear-stress-gauge housing.

\section{A. Pressure and Temperature Measurements}

There are a total of 107 static-pressure ports distributed along the plate as shown in Figure 5. The pressure ports are 6.3 $\mathrm{mm}$ diameter inserts with a $0.3 \mathrm{~mm}$ orifice and are inserted into the plate before the surface is finished. The locations of the fifteen thermocouples are also shown in Figure 5. These are also mounted on inserts that fit into the plate. With these arrays, the wall conditions can be accurately monitored. Although the $C_{p}$ and $\Delta C_{p}$ are not expected to exceed $5 \%$, the high dynamic pressures 
Final Report: Design of High-Reynolds

Number Flat-Plate Experiments in the NTF

Page 11

produce maximum differential pressures of around 0.1 atm. In order to satisfy Equation (8) for zero-pressure-gradient flow, we need to resolve 0.01 atm for a $150 \mathrm{~mm}$ gauge spacing. The lower test conditions could have pressures one-tenth of these numbers. These values are well within the state of the art.

\section{B. Shear-Stress Gauge}

The skin-friction coefficient will be measured with a novel shear-stress gauge developed at NASA Langley Research Center. ${ }^{18}$ The gauge consists of a $9.4 \mathrm{~mm}$ diameter floating disk placed in a housing $27 \mathrm{~mm}$ in diameter. The disk is connected to a four-bar linkage which in turn has a LVDT device with a restoring force motor to measure displacement. The gauge, shown in Figure 6, is made entirely of aluminum and has been successfully tested (without a heater) in the $0.3 \mathrm{~m}$ Transonic Cryogenic Tunnel. Local skin friction was measured ${ }^{18}$ at temperatures of $100^{\circ} \mathrm{K}$, $150^{\circ} \mathrm{K}, 200^{\circ} \mathrm{K}$, and $300^{\circ} \mathrm{K}$, and the data overlapped reasonably well over the different ranges. For the present experiments, the skin friction will be a maximum at the forward location under conditions of highest dynamic pressure giving $\tau_{*} \approx 303 \mathrm{~Pa}(0.044$ psi) or a load of $0.02 \mathrm{~N}(.0049 \mathrm{lb}$.$) . A total of twelve gauges$ ( 6 each in two load ranges of $0.025 \mathrm{~N}$ and $0.0025 \mathrm{~N}$, respectively) are used at the six locations shown in Figure 5. The shearstress housings (without shear-stress gauges) can be used for boundary-layer instrumentation as described below. The housings are placed in the plate before the surface is finished.

\section{Hot-Wire Measurements}

The use of hot-wire anemometers in this flow environment presents other major problems. First, the high dynamic pressures may require using much smaller hot wires such as 2 micron diameter instead of the usual $5 \mathrm{micron.}$ Second, the careful work of Stainback et al.19 shows that contrary to other flows, the sensitivity coefficients for velocity and density are not the same and hence separation of the velocity, density, and temperature fluctuations proves to be very difficult. Stainback et al.19 suggest the use of multiple-wire probes under simultaneous sample and hold measurements.

Figure 7 is a sketch of a hot-wire rake that is driven by a lead screw within the shear-stress housing. In this way, the permanently-mounted housing for the shear gauges can also be used for the hot-wire apparatus. The lead screw will be driven by a stepping-motor on the back of the plate. The lead screw and the anti-backlash bushing will be made out of Nitronic 60 stainless steel that has been proven successful in the NTF environments. The six hot wires will be calibrated with the stepping-motor angular displacement. A positive backup measurement will be used by employing the LVDT concept parallel to the motion of lead screw. 
Final Report: Design of High-Reynolds

Number Flat-Plate Experiments in the NTF

Page 12

Because of the versatility of this technique, other measurement instruments are used, such as the device by Ng and Epstein ${ }^{20}$ which is implemented to measure freestream total temperature and pressure fluctuations. A total-pressure tube is also mounted in the shear-gauge housing.

The use of a traverse-controlled device that would make hotwire measurements over the entire plate is quite desirable when compared to measurements at six fixed locations. The development of such a device in such a severe environment is by no means trivial, and we continue to examine the problem. However, because of the extremes of temperature and dynamic pressure, the implementation of a boundary-layer "mouse" that can move a hot wire in steps of $25 \mathrm{pm}$ may take longer to develop than a remove LDV system for NTF.

\section{Motion and Load Measurements}

An accelerometer is used to measure plate vibration, and its signal is correlated with the hot-wire measurements. The strain gauges are mounted to the back of the plate and monitor plate deflection under load conditions. Remote model-deformation instrumentation are also available.2l These measurements are necessary not only for certifying the test environment but for safety reasons as well.

\section{Conclusions}

It is shown that it is feasible to conduct zero-pressuregradient measurements on a flat plate in the NTF under extreme conditions. Criteria are developed for the conduct of such tests.

\section{Acknowledgements}

This work is supported under NASA Cooperative Agreement NCC1-71. The author would like to thank J.B. Peterson for his continuous help, and C. May, K. Herbert for carrying out the computations of the blockage effects, and Dr. E. C. Anderson for his help with the viscous calculations.

\section{References}

1 Polhamus, E.C., "The Large Second Generation of Cryogenic Tunnels," Astro \& Aero., Vol. 19, No. 10 (1981), pp. 38-51.

2 Winter, K.G., Smith, K.G., and Gaudet, L., "Measurement of Turbulent Skin Friction at High Reynolds Numbers at Mach Numbers of 0.2 and 2.2," AGARDOgraph 97 (May 1965), pp. 97-123. 
Final Report: Design of High-Reynolds

Number Flat-Plate Experiments in the NTF

Page 13

3 Karman, T. von, "Mechanische Annlichkeit und Turbulenz," NACA-TM-611 (1931).

4 Schoenherr, K.E., "Resistance of Flat Surfaces Moving Through a Fluid," Trans. Soc. Nav. Arch., Marine Eng. Vol. 40, $(1932)$, p. 279 .

5 Schultz-Grunow, W., "Nues widerstandsgesetz fur glatee Platten," NACA-TM-986 (1941).

6 Smith, D.W. and Walker, J.H., "Skin Friction Measurements in Incompressible Flow," NASA-TR-R26 (1959).

? White, F.M., Viscous Fluid Flow, McGraw-Hill (1974).

8 Fuller, D.E., "Guide for Users of the National Transonic Facility," NASA-TM 83124 (July 1981).

: Kilgore, R.A., Goodyear, M.J., Adcock, J.B. and Davenport, E.E., "The Cryogenic Wind Tunnel Concept for High Reynolds Number Testing," NASA-TND-7762 (November 1974).

10 Adcock, J.B. and Johnson, C.B., "A Theoretical Analysis of Simulated Transonic Boundary Layers in Cryogenic Nitrogen Wind Tunnels," NASA-TP-1631 (March 1980).

11 Lin, J.C., Weinstein, L.M. and Watson, R.D., "Drag of Transverse Wave-Shaped Surface Corrugations," AIAA Paper No. 830228.

12 Schlichting, H., Boundary-Layer Theory, 7 th Edition, McGraw-Hill (1979).

13 Bristow, D.R., "Development of Panel-Method Codes for Subsonic Analysis," NASA Contractors Report 3234, NASA Langley Research Center (February 1980).

14 Anderson, E.C. and lewis, C.H., "Nonreacting and Equilibrium Chemically Reacting Turbulent Boundary-Layer Flow," Int'l. J. Num. Meth. Eng., Vol. 7 (1973), pp. 3-15.

15 May, C. and Saric, W.S., "A Coupled Viscous/Inviscid Code for Model Interference Effects," in preparation.

16 Nagib, H., Private Communication (February 1984).

17 Gentry, G.L., Jr., Igoe, W.B. and Fuller, D.E., "Description of 0.186 Scale Model of High-Speed Duct of National Transonic Facility," NASA-TM 81949 (May 1981).

18 Tcheng, P., NASA Private Communication (1983). 
Final Report: Design of High-Reynolds

Number Flat-Plate Experiments in the NTF

Page 14

19 Stainback, D.C., Johnson, C.B. and Basnett, C.B., "Preliminary Measurements of Velocity, Density, and Total Temperature Fluctuations in Compressible Subsonic Flow," $A I A A$ Paper No. 83-0384.

20 Ng, W.F. and Epstein, A.H., "High-Frequency Temperature and Pressure Probe for Unsteady Compressible Flows, "Review of Scientific Instruments, Vol. 54, No. 12 (December 1983), pp. 1678-1683.

21 Burner, A.W., Snow, W.L. and Goad, W.K., "Video Model Deformation System for the National Transonic Facility," NASA-TM 85681 (August 1983). 


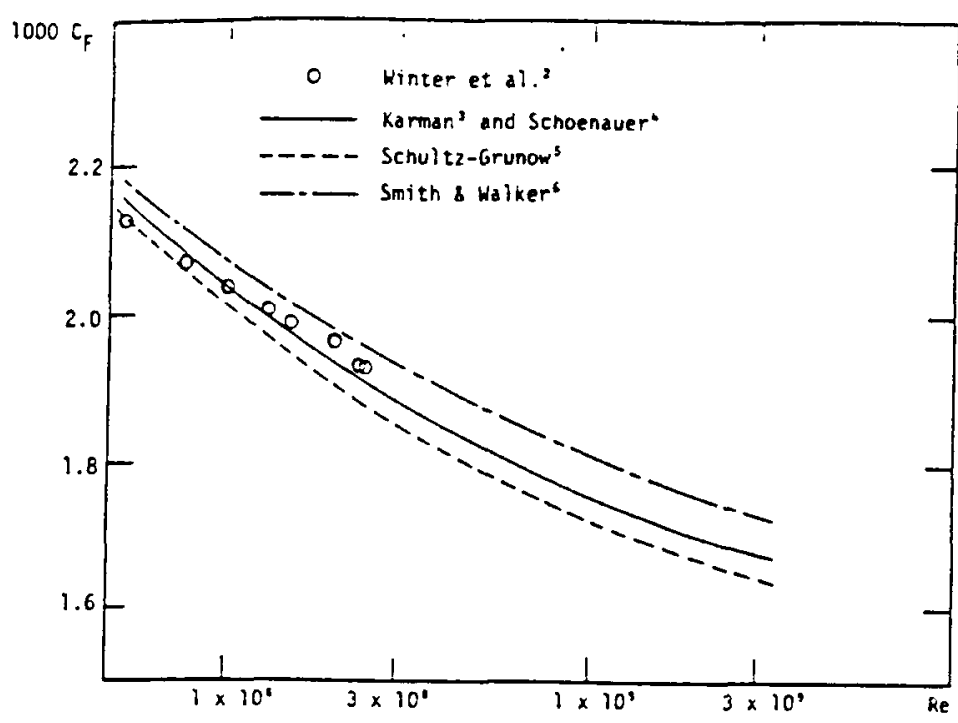

Figure 1. Average skin-friction coefficient $C_{F}$ as a function of Reynolds Number.
ORIGNAL PAGE IS
OF POOR QUALTY

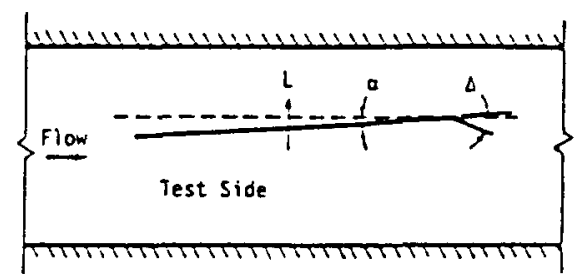

$L$ : lift (positive direction shown)

$a$ : angle of attack (nenative a shown)

$\Delta$ : flap anqle (neative $\Delta$ shown: "down flap")

Figure 2. Schematic of plate inside tunnel.

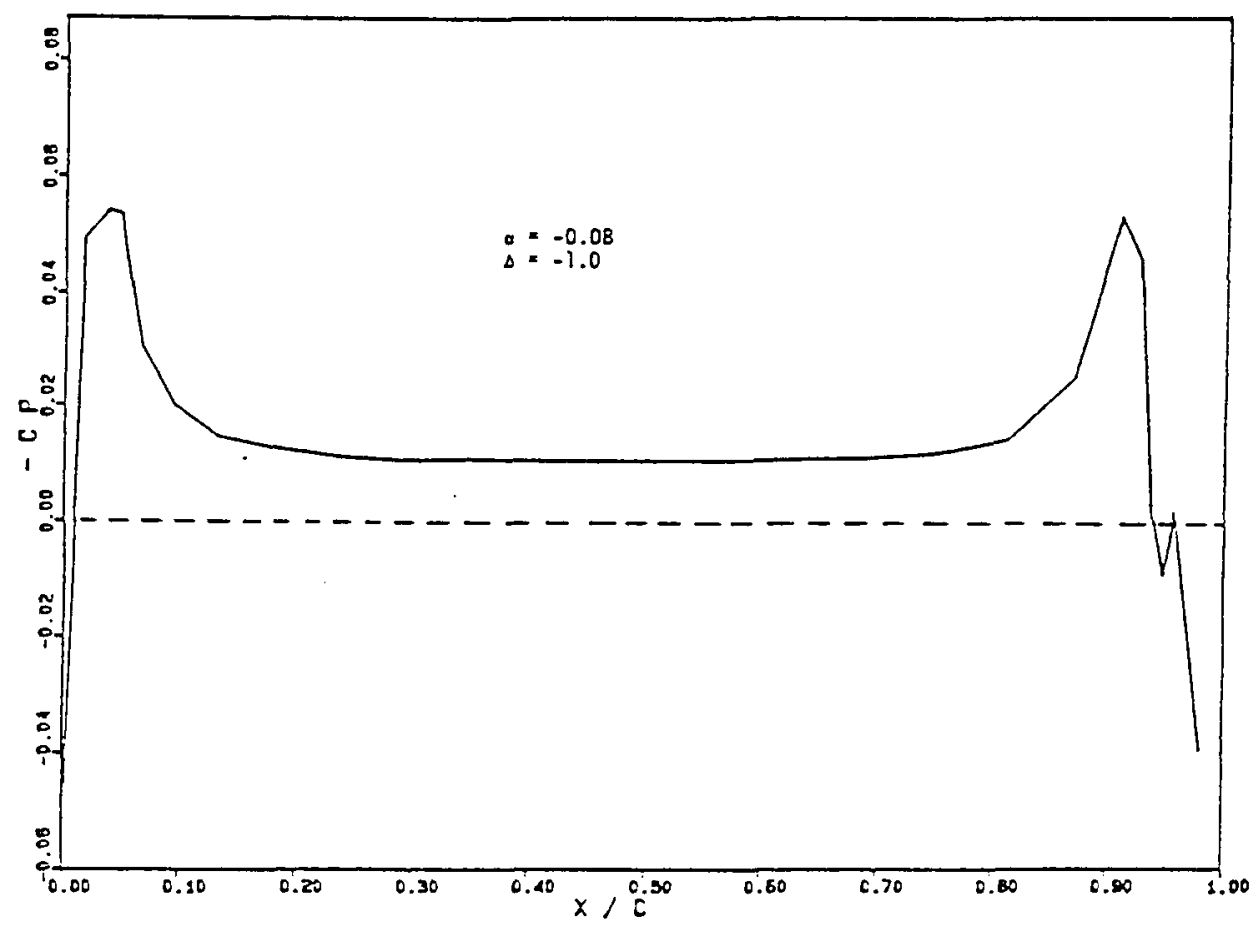

Figure 3. $C P_{0}$ vs $x / C$ on the test side of the plate for conditions of $c=-0.08^{\circ}$ and $\Delta=-10^{\circ}$ with displacement-thickness effects included. 


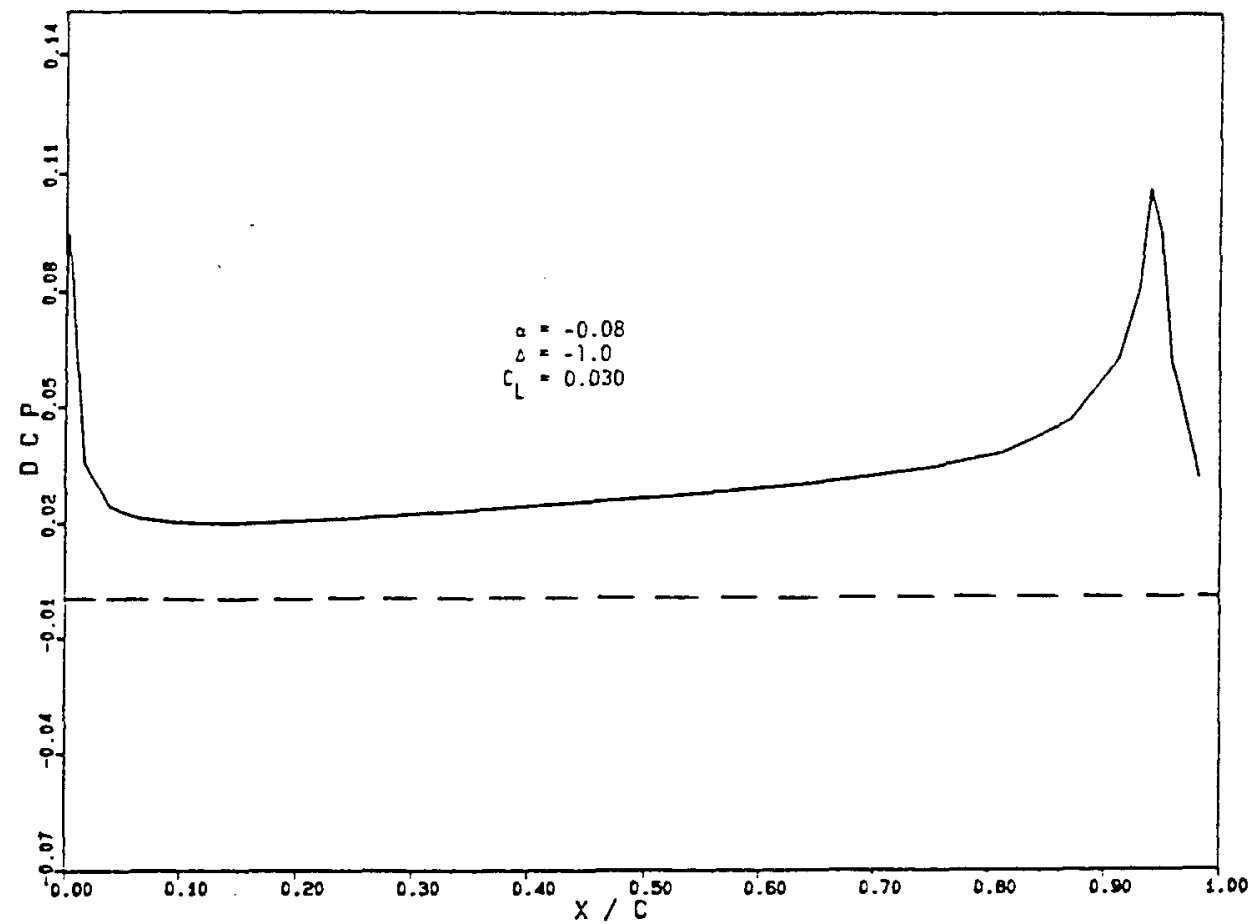

Figure 4. $\triangle C p_{0}$ vS $x / C$ for conditions of $\alpha=-0.080$ and $\Delta=-1.0^{\circ}$ with displacement thickness effects included. $C_{L_{0}}=+0.030$.

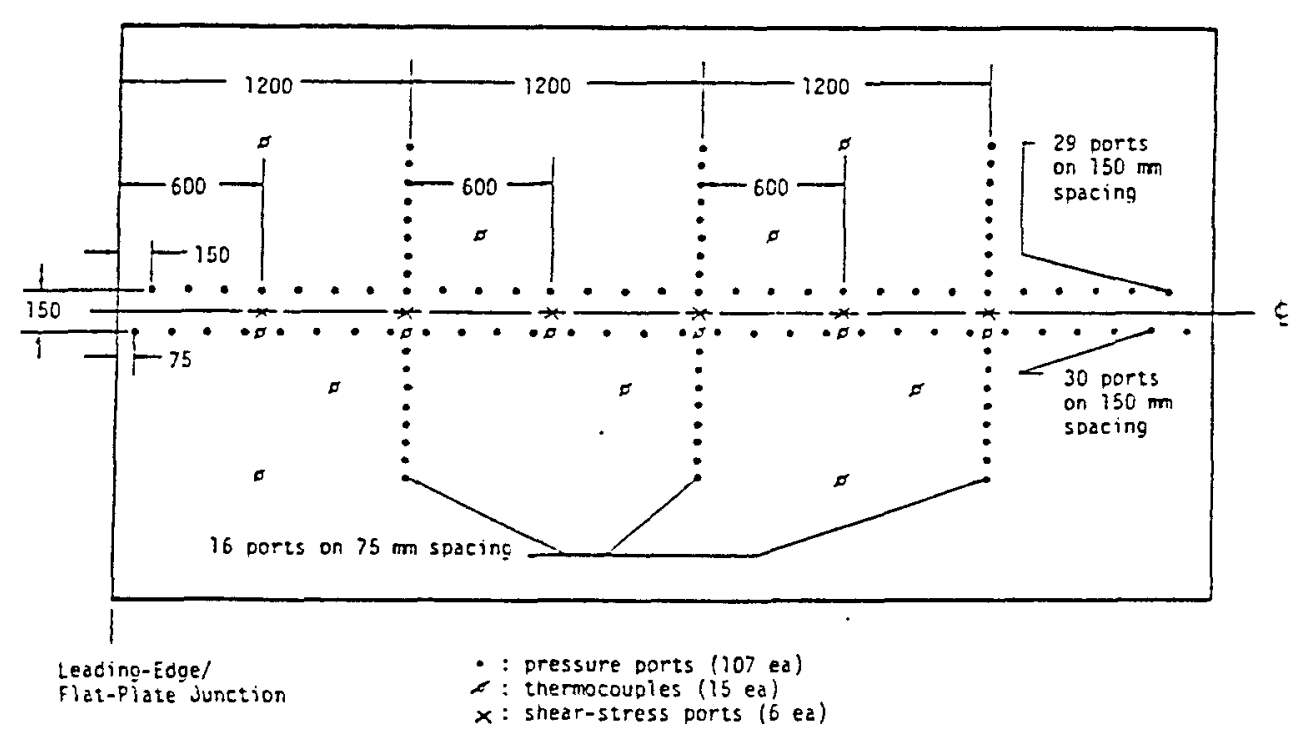

Figure 5. Location of instrumentation on flat plate. 


\section{ORIGNAL PAGE IS \\ OF POOR QUALTY}

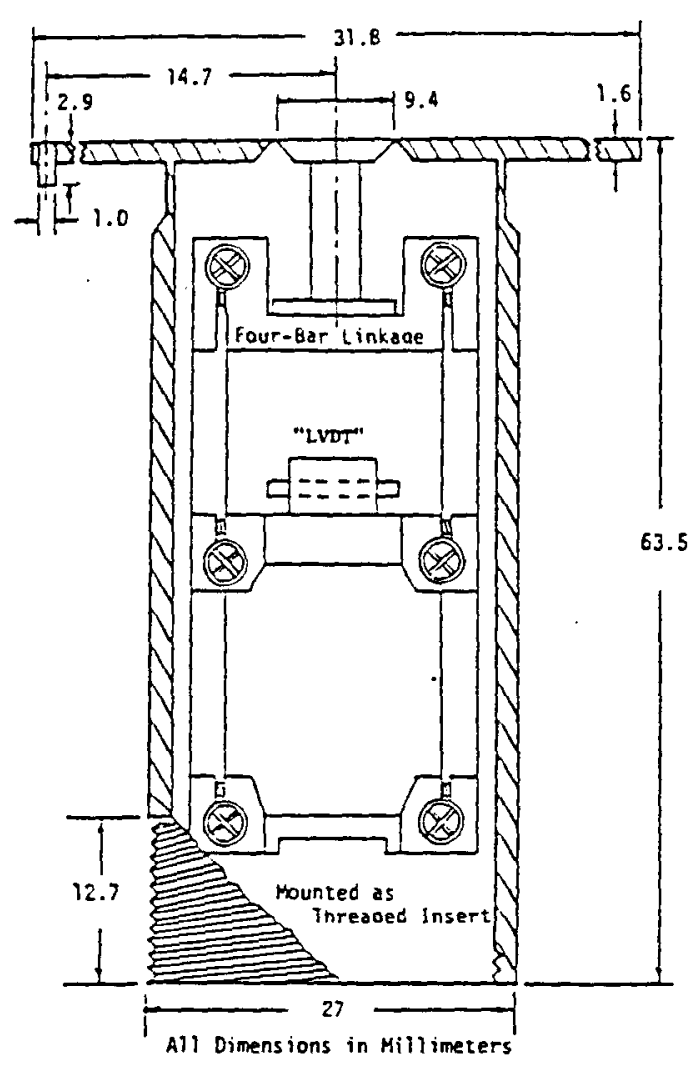

Figure 6. Schematic of shear-stress gauge.

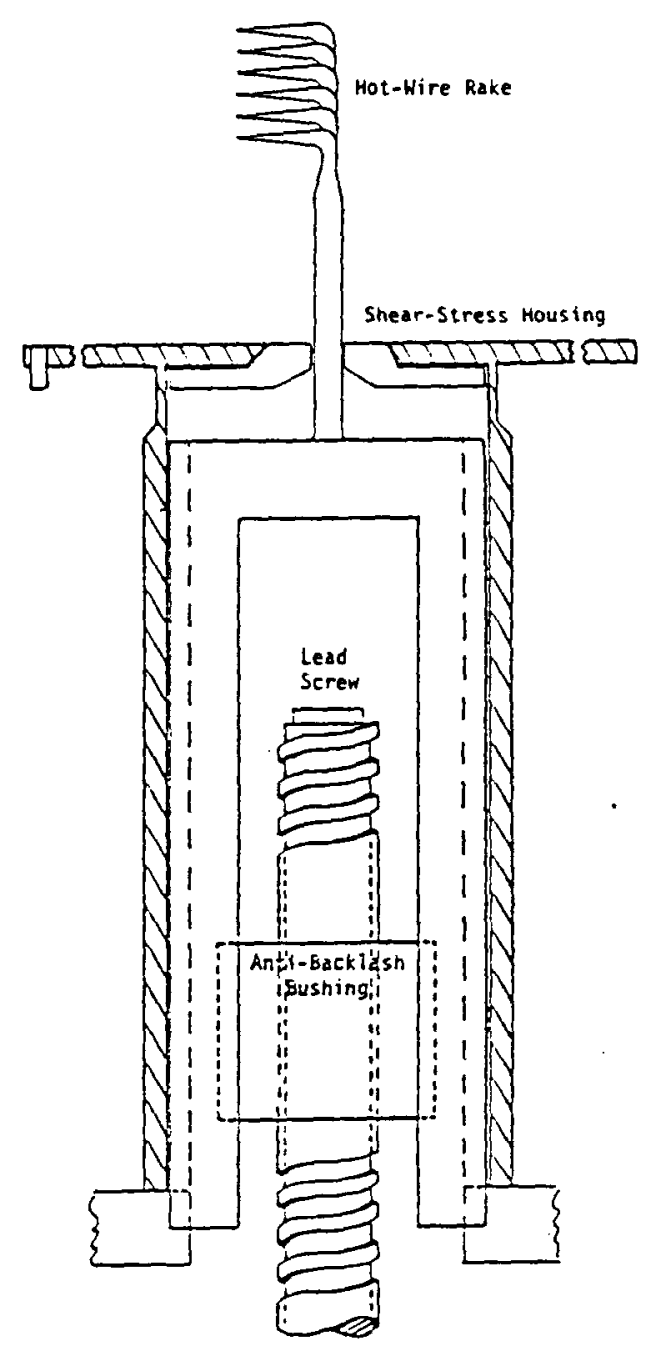

Figure 7. Schematic of hot-wire support and traverse. (Not to scale.) 